\title{
AS A POTENTIAL HYDRAULIC FLUID: CORN OIL BEHAVIOR CHARACTERISTICS EXAMINATION
}

\author{
Mohammed Hassan Jabal ${ }^{1,2,}$, Abdulmunem R. Abdulmunem¹, Hussain Saad Abd ${ }^{1}$
}

\begin{abstract}
Low toxicity, high biodegradability, renewability and high viscosity index of the plant (vegetable) oils made it have immense potential to replace the mineral cooling fluids. This study aims to evaluate the wear and friction behaviour characteristics of the corn fluid as a renewable bio-fluid resource. Base on the ASTM G-99 standard, behaviour characteristics of fluid were examined in terms of kinematic viscosity, friction force, coefficient of friction, wear scar diameter, and flash temperature parameter. Each experiment was do during one hour and $800 \mathrm{rpm}$ as a rotation speed of disk and under four different loads 5,10,15,20 $\mathrm{kg}$ using the ball on disk tester, the (Mobil hydraulic fluid 424) used as a mineral cooling hydraulic fluid sample for compared the results. Based on the results, it was found that under low loads $(5$ and $10 \mathrm{~kg}$ ) the performance of vegetable fluid (corn) is better than the mineral hydraulic fluid (463.38 \& $469.84 \mu \mathrm{m}$ under $5 \mathrm{~kg}$ and $567.1 \& 593.74 \mu \mathrm{m}$ under $10 \mathrm{~kg}$ respectively), also the values of friction coefficient of vegetable fluids were lower under high load as in the case of normal load $20 \mathrm{~kg}$., which was 0.0159 for the corn and 0.0230 for the mineral fluid. Finally, it is concluded that the corn fluid could be an alternative renewable working cooling fluid due to its adequate performance.
\end{abstract}

Keywords: Cooling fluid, Vegetable fluid, Viscosity, Friction coefficient, Wear diameter

\section{INTRODUCTION}

The working fluids play a large and important role in most mechanical engineering and industrial applications, whether as a metal working fluids, lubricating oils, cooling fluids or hydraulic liquids for transfer the motion and energy. Because of the rapid development of engine industry technology and the ease of production the mineral fluids from crude oil, Hydraulic and working fluids extensively utilized today are mineral based liquids or synthetic fluids and the working fluids properties have been optimized to suit the systems, motor, equipment's requirements they are widely used. However, increasing the environmental problems because of the pollution (approximately 12 million tons of mineral fluids waste are released into rivers, agricultural land and environment) and growing interest in the environment have led to increased search and develop for new and environmentally friendly sources of working fluids, lubricant and oils that cause relatively less damage to the environment and make them compatible with requirements of the machines, these liquids (bio-fluids) are classified as renewable, sustainable resources ,natural, biodegradability and non- toxic [1-4].

With the beginning of the last century, there have been global attempts to test vital biodegradabilityfluids such as plant (vegetable) oils as alternatives to mineral fluids in industrial and engineering fields which being environmentally friendly [5]. Most studies have shown that vegetable fluids have potential use as biodegradable fluids in different applications which including hydraulic fluids, lubricant and working fluids [6;7].In reviewing the literature, various studies related to the bio-fluids properties have been carried out for example: evaluated the characterization of the palm oil and palm olein oil (vegetable fluids) as a metal shaping liquid [8; 9] and investigated the potential of plant fluids as a bio-hydraulic fluid [10;11]. As a hydraulic fluid, Physical properties of the empty bunches of fruit and jatropha oil were examined using the four-ball machine [12]. Most previous studies have found that plant oil has shown satisfactory results and has the potential to be widely used in mechanical engineering and industrial applications. Blend of the palm olein with the (TertiaryButyl-Hydroquinone) as anti-oxidation was investigated as a bio-fluid by using the four- ball tester, the outcomes revealed that the additional (TBHQ) exhibited reduction in friction coefficient and provide a smooth

\footnotetext{
This paper was recommended for publication in revised form by Regional Editor Hussein A. Mohammed

${ }^{1}$ Department of Electromechanical Engineering), University of Technology, Iraq Baghdad.

2 Faculty of Mechanical Engineering, Universiti Teknologi Malaysia, Johor, Malaysia

${ }^{*}$ E-mail address: 50124@uotechnology.edu.iq

Orcid id: 0000-0001-5774-5212, 0000-0001-6954-3546

Manuscript Received 31 May 2019, Accepted 23 September 2019
} 
surface roughness. In another study the tribological properties of the palm-oil-based nano fluid which was blended with $(\mathrm{CuO})$ nanoparticles by using the pin on disk tribometer, the outcomes show that the properties of the palm-oil-based fluid were improved with the presence of copper oxide nanoparticles, showing huge reductions in coefficient of friction and the diameter of wear scar[13;14] .This paper investigates the corn oil behavior characteristics as a potential hydraulic bio-based fluid under four different loads 5,10,15,20 kg using the ball on disk tester.

\section{EXPERIMENTAL METHODOLOGY Apparatus}

For carry out the required tests in this investigation, the ball on disk machine as shown in Figure.1 was utilized $[15 ; 16]$. It is an integrated rig managed by a specific data acquisition system through a personal computer (PC), this machine can be used to conduct a lot of tests concerning the operating fluids, lubricant and hydraulic fluids of all kinds under a broad range of tests and conditions. This device consists of a metal flat disc $(165 * 8 \mathrm{~mm}$ Stainless steel) driven by an electric motor at a specified rotational speed a fixed metal ball (EIS52100 chrome-alloy steel. $12.7 \mathrm{~mm}$ diameter of ball, 25 grade Eb and 64-66 Hardness-R.WC hardness test) is installed on the disk under specific load by using a set of weights. According to the standard test (ASTMG-99), Each experiment was do during an hour, 800rpm as a rotation speed of disk, oil temperature was set under $75^{\circ} \mathrm{C}$ and under four different normal loads $5,10,15,20 \mathrm{~kg}$.
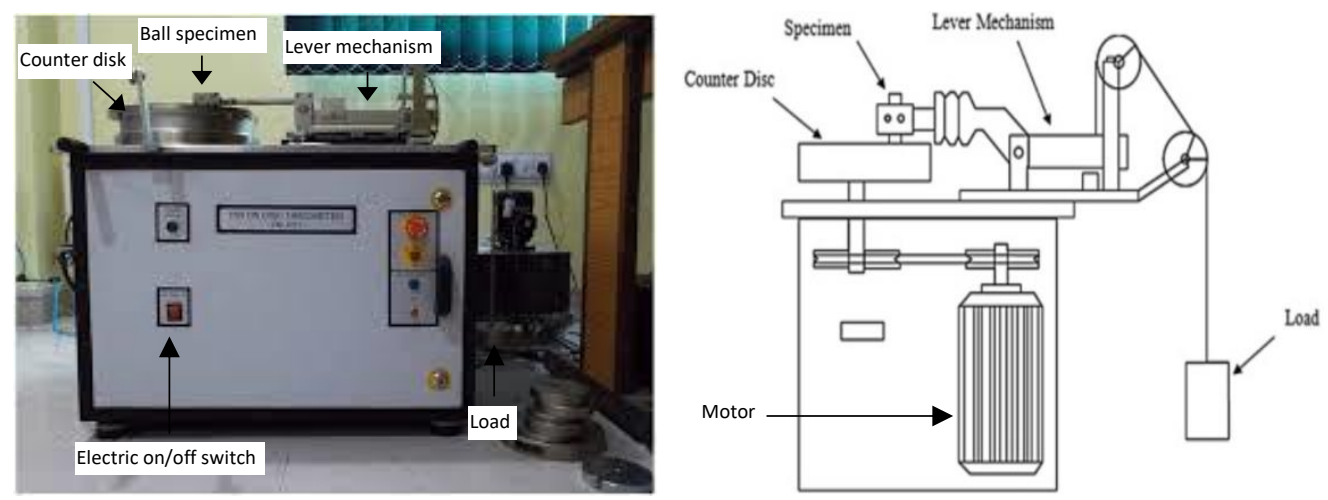

Figure 1. Ball on disk tester machine

\section{Fluid Samples}

In current experimental work, two types of fluid were utilized: first the bio-fluid which was the vegetable corn oil and the second sample was the mineral hydraulic fluid (Mobil hydraulic fluid 424). For, each test, $10 \mathrm{ml}$ of fluid was used.

\section{Viscosity and Viscosity Index}

Mineral -based hydraulic fluid has a variety of desirable characteristics, including lubricating and antiwear and friction properties, so it is often the preferred fluid for hydraulic systems. For these uses, petroleum fluid is highly refined to remove undesirable chemicals while other chemicals, such as additives, are added to improve the oil's performance. One of these performances index is a viscosity and viscosity index. Because oil's viscosity changes with temperature, it is always expressed at a reference temperature, usually $100^{\circ} \mathrm{C}$ and $40^{\circ} \mathrm{C}$. Viscosity is measured with a viscometer.

Viscosity index numbers (unite less) are devised on a scale of zero to 100, which indicates the extent of viscosity change. Thus 0 indicates a fluid with the greatest change over a certain temperature while 100 indicates a fluid with the least change over a certain temperature. All other fluids fall within these extremes.

\section{Wear Scar Diameter}

To study the performance characteristics of vegetable fluid (corn oil) and compare the performance with the characteristic of mineral hydraulics fluid in this study, diameter of the wear scar (WSD) in the ball surface 
was measured after 60 mins of operation the ball on disk machine, where the diameter was determined by using the digital electronic microscope (high magnification).

\section{Friction Force and Coefficient of Friction}

By using the Winducom program, which is connected by the personal computer to the ball on the disk machine, the different values of the friction force are recorded during the test period ( 1 hour). The recorded results show that the friction force starts increasing gradually with the start of the test and after a short period (5 mints) the friction force values begin to stabilize. Using the measured friction force values, the value of the friction coefficient $(\mu)$ is calculated [14] using the following equation:

$$
\mu=F \cdot N^{-1}
$$

\section{Flash Temperature Parameter (FTP)}

The flash temperature or the flash temperature parameter (FTP) is the most important characteristics that must be calculated for the fluids because it gives a clear representation of the ability of the fluid to withstand operating conditions or test before the collapse [15]. High flash value gives positive perception of fluid efficiency to work in different working conditions.

Equation 2 can be used to calculate a value of the flash temperature parameter:

$$
F T P=\frac{W}{(W S D)^{1.4}}
$$

\section{RESULT AND DISCUSSIONS}

Behavior characteristics (viscosity - temperature relationship, dimensions of the wear area, anti-friction performance and the parameter of the flash temperature) for the corn fluid (as a renewable bio-fluid) and mineral hydraulic fluid were examined accorediting to the ASTM G99 standard and the all results were displayed through a variety of the shapes (2-7) and discussed in subsequent paragraphs separately.

\section{Viscosity - Temperature Relationship}

The viscosity of fluids and oils is an important characteristic which plays an important role directly or indirectly in the performance of machines and engines. In this study the kinetic viscosity of the fluid samples was examined at different temperatures 40,75 and $100^{\circ} \mathrm{C}$. The relationship between the viscosity (including the error bares series with $5 \%$ value) \& temperature obtained from this test appears in Figure 2.

From this figure, can observe that there is an inverse relationship between the temperature and viscosity for the both fluid samples (plant and mineral fluid) [16;17]. From same figure, also could be observed that there is a convergence of viscosity values for both types of fluids (corn and mineral hydraulic) at high temperatures. in addition, The figure 2. shows indirectly that the viscosity index for vegetable fluid (corn) was higher than the viscosity index value for the mineral hydraulic fluid.

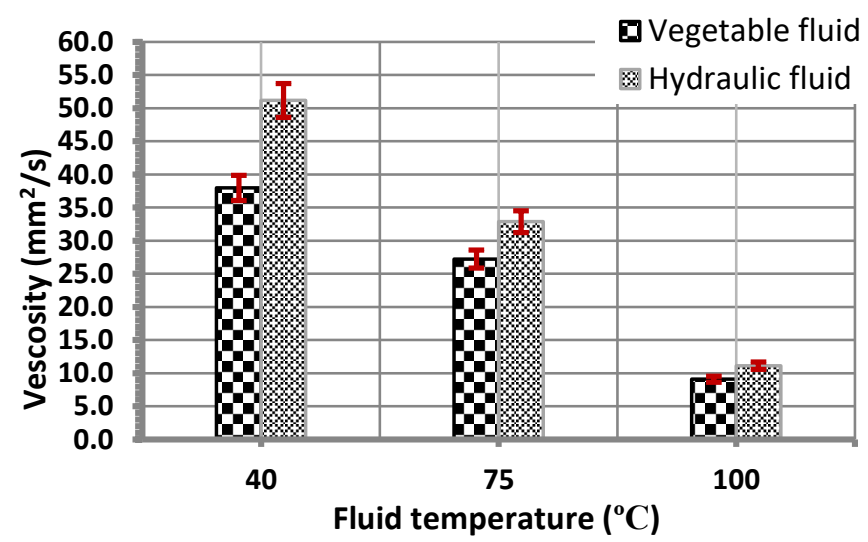

Figure 2. Viscosity and temperature relationship for fluid samples 
Journal of Thermal Engineering, Vol. 7, No. 2, Special Issue 13, pp. 215-221, February, 2021

Yildiz Technical University Press, Istanbul, Turkey

\section{Wear Scar Diameter}

After determining the diameters of the wear area for the research samples (three balls lubricated with hydraulic and corn fluid) under different normal loads within 60 minutes (test period) by using the SEM scanning electron microscope, these results were presented graphically as shown in Figures 3 ( $a, b, c$ and d) and 4. By looking at these figures, it could noticeable that there is an increase in the value of the wear diameter over time for both fluid samples (vegetable and mineral), then the value of the wear diameter become more stabilizes. In addition, could note that in the low loads ( 5 and $10 \mathrm{~kg}$ ) the performance of vegetable fluid (corn) is better than mineral hydraulic fluid $(463.38 \& 469.84 \mu \mathrm{m}$ under $5 \mathrm{~kg}$ and $567.1 \& 593.74 \mu \mathrm{m}$ under $10 \mathrm{~kg}$ respectively). On the other hand, mineral hydraulic fluid appears to perform better in terms of the diameter of the wear scar compared to corn fluid under high loads 15 and $20 \mathrm{~kg}(657.38 \& 694.47 \mu \mathrm{m}$ under $15 \mathrm{~kg}$ and $740.41 \& 750.62 \mu \mathrm{m}$ under $20 \mathrm{~kg}$ respectively), This behavior occurs because the metallic soap film in the vegetable oil is rubbed away from the contact area under high loads.

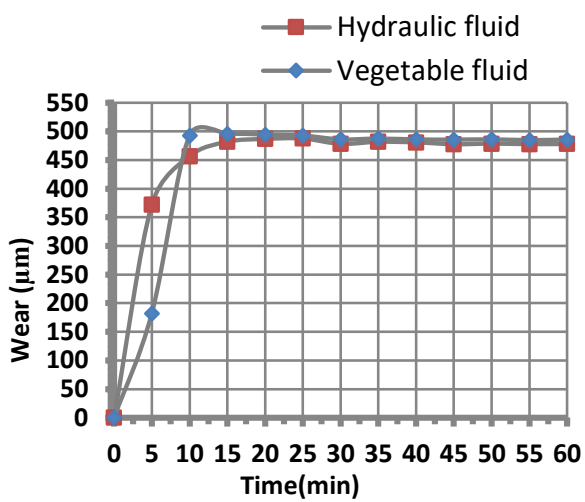

a) $\rightarrow$ Hydraulic fluid

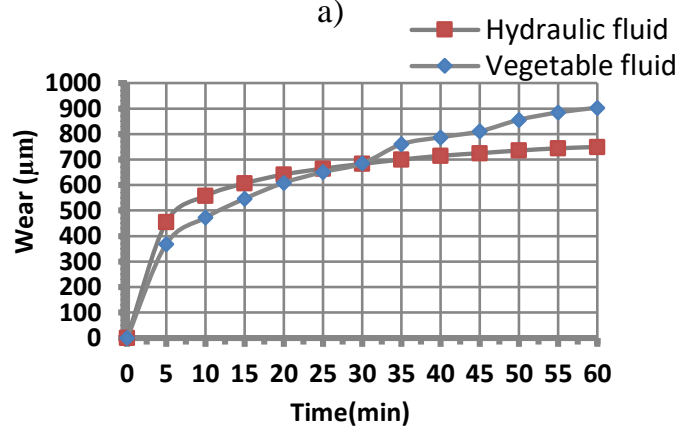

c)

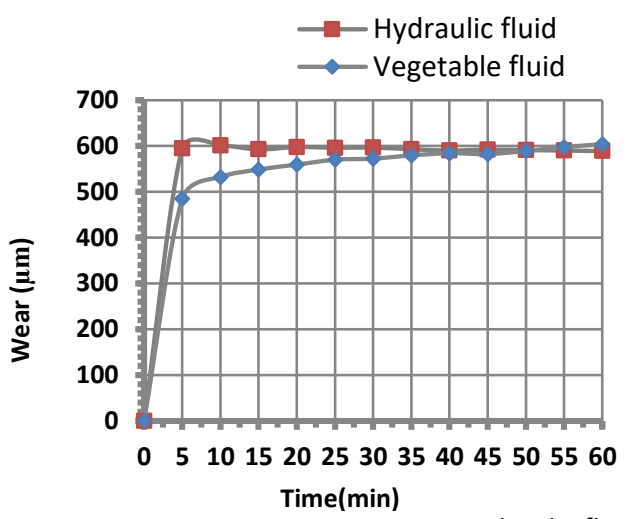

b) $\rightarrow$ Hydraulic fluid

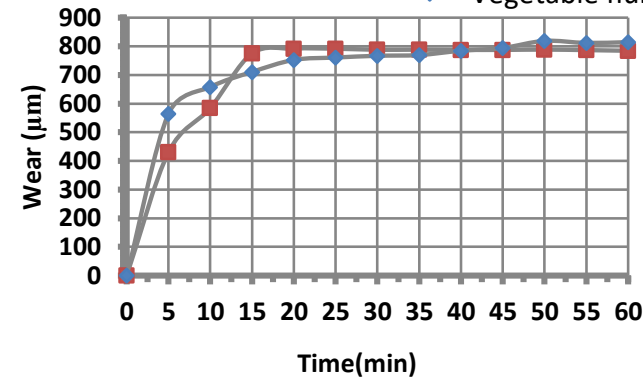

d)

Figure 3. Wear scar diameter and time relationship under: a) $5 \mathrm{~kg}$, b) $10 \mathrm{~kg}$, c) $15 \mathrm{~kg}$, d) $20 \mathrm{~kg}$

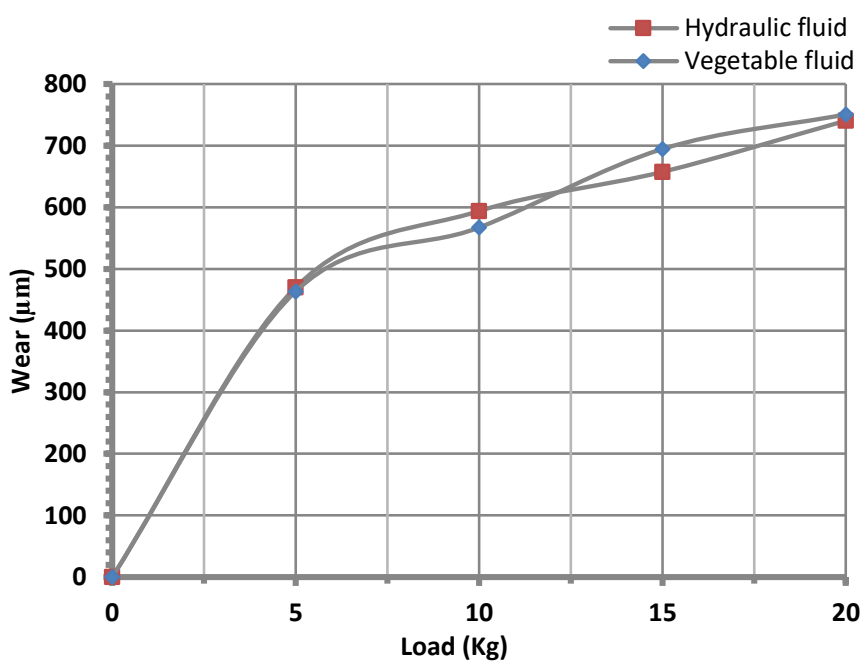

Figure 4. Wear scar diameter and load relationship 


\section{Coefficients of Frictions}

After calculating the values of friction coefficient using Equation (1) and depending on the values of friction torque which recorded directly from the ball on disk machine by using the data acquisition system, a comparison was made between the values of the friction coefficients for the vegetable and mineral fluids under various loads which presented in the figures $5(\mathrm{a}, \mathrm{b}, \mathrm{c}$ and $\mathrm{d})$ and 6 under different loads.

From the two Figures 5 and 6 could be observed that the values of the friction coefficient began decreasing gradually over time and also noted that the values of friction coefficient of vegetable fluids are lower at high load as in the case of normal load $20 \mathrm{~kg}$., which was 0.0159 and 0.0230 for the corn and mineral fluid respectively, this result can be attributed to the long chain fatty acid and the esters which are known as active anti-friction materials [18-25].

Basing on the outcomes in the figures 5 and 6 can be depended the reality, that the biodegradable fluid like the corn fluid has powerful action as a friction reducing (anti-friction fluid).

\section{Flash Temperature Parameter}

Basing on the diameters of the wear area (average value of the three diameters for each test) under various normal loads $(5-20 \mathrm{~kg})$ and by utilizing the equation No 2, results of the flash temperature parameters (FTP) were calculated and presented graphically as shown in Figures 4. from this figure could be seen that there is an increase in the value of the flash temperature parameters with increasing the value of the normal load for both fluid samples (corn and the mineral hydraulic fluid), and could be seen also, the performance of vegetable fluid (corn) and mineral fluid were comparable to each other under most the values of loads (14.67 and 14.39 for the corn and hydraulic fluid respectively under $5 \mathrm{~kg}$ and 29.88 and 30.46 for the corn and hydraulic fluid respectively under $20 \mathrm{~kg}$ ).

In addition, could be observed that under low normal load (5 and 10kg) vegetable fluid (corn) shown preferable performance (lubricity) compared to the hydraulic fluid sample (22.12 and 20.74 for the corn and hydraulic fluid respectively under $10 \mathrm{~kg}$ ).

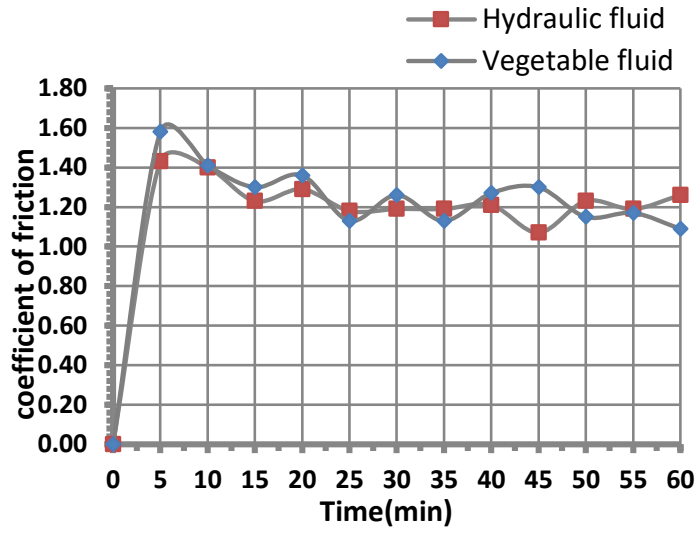

a)

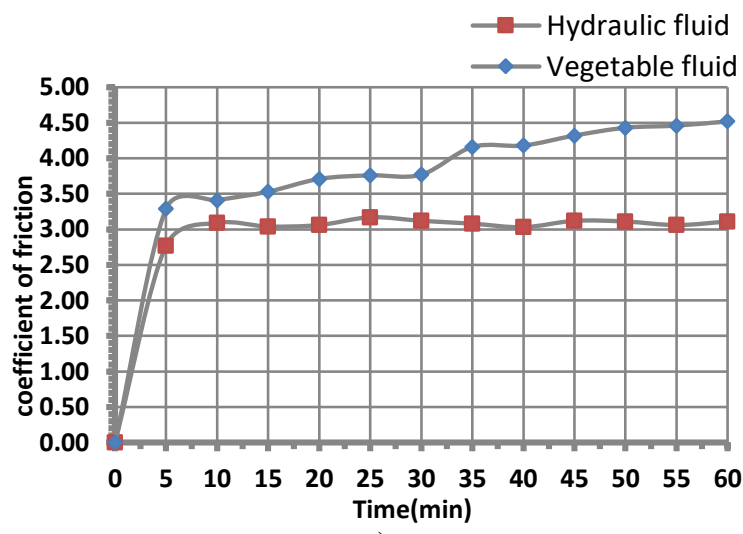

c)

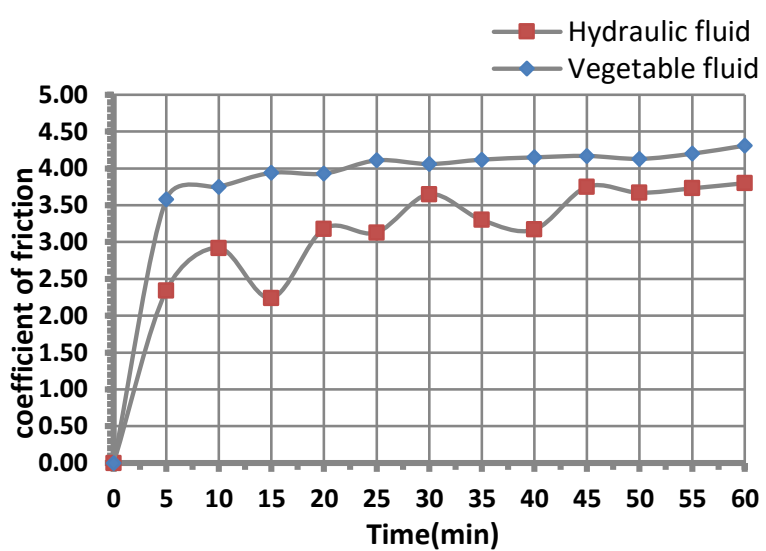

b)

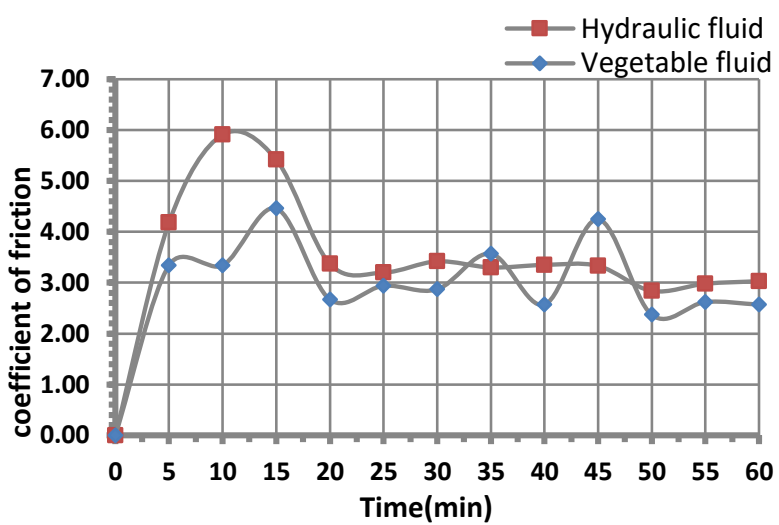

d)

Figure 5. Coefficient of friction and time relationship under: a) $5 \mathrm{~kg}$, b) $10 \mathrm{~kg}$, c) $15 \mathrm{~kg}$, d) $20 \mathrm{~kg}$ 


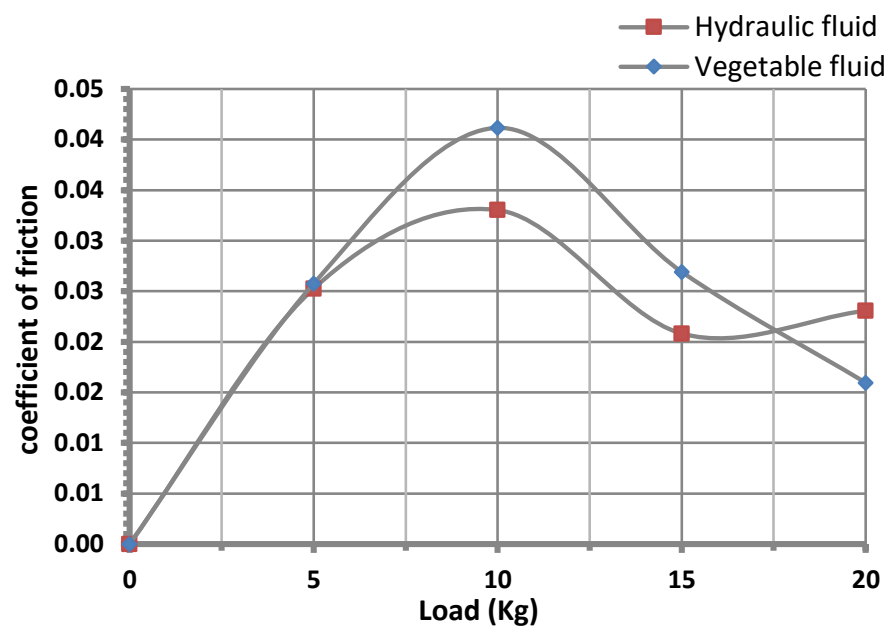

Figure 6. Coefficient of friction and load relationship

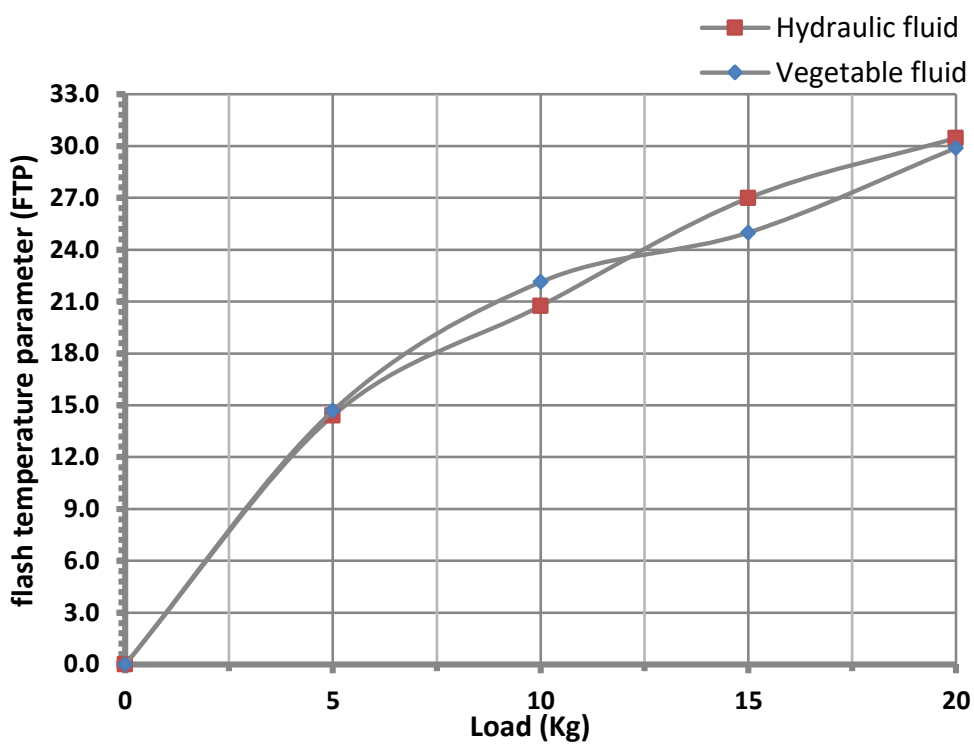

Figure 7. Flash temperature parameter and load relationship

\section{CONCLUSIONS}

Basing on the results, it can be concluded that:

- Values of the wear scar diameters versus time and under low normal loads indicate good anti -wear performance of the corn fluid compared to the mineral hydraulic fluid.

- Results of the coefficient of friction under high loads referred to a lower value of coefficient of friction (good anti-friction performance) compared to the mineral hydraulic fluid.

- The overall evaluation results (viscosity, wear scar diameter, coefficient of friction and the flash temperature parameter) of the corn fluid shows adequate performance as an alternative renewable working fluid.

\section{NOMENCLATURE}

$\begin{array}{ll}\mu & \text { frictions coefficients } \\ \mathrm{F} & \text { frictional force }(\mathrm{N}) \\ \mathrm{N} & \text { apply loads }(\mathrm{N}) \\ \mathrm{W} & \text { applied loads }(\mathrm{kg}) \\ \mathrm{WSD} & \text { scar diameter of wear }(\mathrm{mm})\end{array}$


Journal of Thermal Engineering, Vol. 7, No. 2, Special Issue 13, pp. 215-221, February, 2021

Yildiz Technical University Press, Istanbul, Turkey

\section{REFERENCES}

[1] Mercurio, P., Kurns, K. A., and Negri, A. Testing the ecotoxicology of vegetable versus mineral based lubricating oils:Degradation rates using tropical marine microbes. Environ Pollut. 2004 May;129(2):16573. doi: 10.1016/j.envpol.2003.11.001.

[2] Bartz, W. J. Lubricants and the environment. Tribology Int 1998. 31:35-47. https://doi.org/10.1016/S0301-679X(98)00006-1

[3] Hotti, S., \& Hebbal, O. (2015). Biodiesel production and fuel properties from non-edible Champaca (Michelia champaca) seed oil for use in diesel engine. Journal of Thermal Engineering, 1(1), 330-336. https://doi.org/10.18186/jte.67160

[4] Joshi, M. (2019). Combustion Analysis of CI Engine Fuelled With Algae Biofuel Blends. Journal of Thermal Engineering, 5 (6), 214-220. doi: 10.18186/thermal.654374.

[5] M. Hassan et al., (2016). The Tribological Characteristics of RBD Palm Olein with Jatropha Oil Blend Using Four-Ball Tribotester with Different Normal Loads, Applied Mechanics and Materials 2016. 819: 499-503. https://doi.org/10.4028/www.scientific.net/AMM.819.499

[6] Golshokouh,I.; Syahrullail,S.;Ani,F.N.;and Masjuki.H.H.(2013). Investigation of Palm Fatty Acid Distillate Oil as an Alternative to Petrochemical Based Lubricant. MPOB Journal 2013.07.01:72-80.

[7] Mohammed Hassan Jabal, Abdulmunem R. Abdulmunem and Hussain Saad Abd. Experimental investigation of tribological characteristics and emissions with nonedible sunflower oil as a bio lubricant, Journal of the Air \& Waste Management Association 2019. 69.1:109-118, doi:10.1080/10962247.2018.1523070.

[8] Ahmed, H. I., Hassan, X. M., \& Abdul, C. A. Performance changes for window type air-conditioner unit the treated to work in an industrial petrochemical environment. Engineering \&amp; Technology Journal 2011.29: 430-447.

[9] Wan Nik, W.B.; Ani, F.N.; and Masjuki, H.H. Thermal stability evaluation of palm oil as energy transport media, Energy Conservation and Management 2005.46: 2198-2215. https://doi.org/10.1016/j.enconman.2004.10.008

[10] Syahrullail, S.; Nakanishi, K.; and Kamitani, S. (2005). Investigation of the effects of frictional constraint with application of palm olein oil lubricant and paraffin mineral oil lubricant on plastic deformation by plane strain extrusion. Journal of Japanese Society of Tribologists 2005.50.12:877-885.

[11] Ing, C.T.; Mohammed Rafiq; A.K.; Azli, Y.; and Syahrullail, S. The effect of temperature on the tribological behavior of RBD palm stearin. TribologyTransactions 2012. 55.055: 539-548. https://doi.org/10.1080/10402004.2012.680176

[12] Hassan, M.; Syahrullail, S.; and Ani, F. N..The tribological characteristics of the cactus and mineral oil blends using four-ball tribotester. Jurnal Teknologi 2016.78.(9-2): 33-38. doi: https://doi.org/10.11113/jt.v78.9652

[13] Jabal M.H.; F.N. Ani; and S, Syahrullail.The Tribological Characteristic of the Blends of RBD Palm Olein with Mineral Oil using Four-ball Tribotester. Jurnal Technology 2014. 69.6:11-14.

[14] Maleque, M.A.; Masjuki, H.H.; and Haseeb, A.S.M.A.(2000).Effect of mechanical factors on tribological properties of palm oil methyl ester blended lubricant. Wear 2000. 239.01:117-125. https://doi.org/10.1016/S0043-1648(00)00319-7

[15] Jabal, M. and Khalefa, M. (2018) "Tribological Characteristics Evaluation of Mustard Oil Blends", Journal of Engineering, 24(3), pp. 1-12. doi: 10.31026/j.eng.2018.03.01.

[16] Hassan, M.; Ani, F.N.; and Syahrullail, S. (2016). Tribological Performance of Refined, Bleached and Deodorised Palm Olein Blends Bio-lubricants. Journal of Oil Palm Research 2016. 28.04: 510-519.

[17] Fattah, F. A., Ariff, M. M., Hassan, J. M., and Nasir, A. F. The Tribological Characteristics of Rubber Seed Oil with Mineral Oil Blends. Malaysian Journal of Industrial Technology (MJIT) 2017.

[18] Mohammed Hassan, Farid Nasir Ani and S. Syahrullail. Tribological Features of Refined, Deodorized, and Bleached Palm Olein with Mineral Oil Blend. Tribology Transactions 2016.59.4: 671-678. https://doi.org/10.1080/10402004.2015.1107928

[19] Hussain, A., Mehdi, S., Ali, A., Adeel, M., Jabal, M., \& Ani, F. Investigation of tribological characteristics of castor oil with mineral oil blends. Journal of Engineering and Applied Sciences (2018, June 30).37.01. https://doi.org/https: //doi.org /10.25211/jeas.v37i1.2688

[20] M. H. Jabal, E. O. Hassoun, A. R. Abdulmunem, F. N. Ani (2019). Experimental Investigation Of The 
Neat Rubber Seed Oil As A Hydraulic Fluid Using Four-Ball Tribotester. Journal of Engineering Science and Technology 2019.14.05:2670 - 2680.

[21] Mohammed Hassan Jabal, Hussain Saad Abd, A. A. Gaddoa, Ibrahim Falih Kadhim, Syahrullail Samion, Ameer S. Shajar and Abdulwahhab A. Hardan - Published under licence by IOP Publishing Ltd,IOP Conference Series: Materials Science and Engineering, Published 1 March 2020 Volume 765, 1st International Conference of Electromechanical Engineering and its Applications (ICEMEA-2020) 25-26 February 2020, Baghdad, Iraq doi:10.1088/1757-899X/765/1/012025

[22] Abd, H. S., Abdulmunem, A. R., Jabal, M. H., Samin, P. M., \& Rahman, H. A. Working Features Evaluation of the Diesel Engine Lubricated with Blends of Renewable Corn Oil and Carbon Nanotubes. Journal of Mechanical Engineering Research and Developments, ISSN: 1024-1752 CODEN: JERDFO 2020. 43.02: 384-395.

[23] Jabal, M. H., Khlefia, M. Z., \& Abdulmunem, A. R. 2018. T Ribological Performance of Mustard Seeds Oil Under Different Loads Using Pin-On-Disk Tribotester. the Iraqi journal for mechanical and materials engineering, 18(4), 527-537.

[24] Jabal, M. H. IC-Engine Performance Dispersed in Non As Bio Lubricant.2018. Volume 9, Issue 13, December 2018.Available online at http://www.iaeme.com/ijmet/issues.asp?JType=IJMET\& VType=9\&IType=13 ISSN Print: 0976-6340 and ISSN

[25] Jabal, M. H., Khlefia, M. Z., Ahmed, I. S., \& Salman, H. D. 2020. Performance Features of The Sunflower Seeds Oil as A Hydraulic Bio Fluid Under Various Normal Loads. Jurnal Teknologi, 82(2). doi: https://doi.org/10.11113/jt.v82.13354 